\title{
Total antioxidant capacity and profiling of polyphenolic compounds in jute leaves by HPLC-DAD
}

\author{
1,*Ali, M.M., ${ }^{2}$ Ahmed, K.S., ${ }^{2}$ Hossain, H., ${ }^{3}$ Roy, B., ${ }^{4}$ Rokeya, B., ${ }^{5}$ Rahman, M.T., \\ ${ }^{2}$ Jahan, I.A. and ${ }^{6}$ Rahman, M.M. \\ ${ }^{1}$ Department of Biochemistry, Bangladesh Jute Research Institute (BJRI), Dhaka-1207, Bangladesh \\ ${ }^{2}$ Chemical Research Division, BCSIR Laboratories, Dhaka, Bangladesh Council of Scientific and Industrial \\ Research (BCSIR), Dhaka-1205, Bangladesh \\ ${ }^{3}$ Department of Chemistry, Hajee Mohammad Danesh Science \& Technology University, Dinajpur, \\ Bangladesh \\ ${ }^{4}$ Department of Pharmacology, Bangladesh University of Health Science, Mirpur-1, Dhaka, Bangladesh. \\ ${ }^{5}$ Jute Seed Production and Research Centre, BJRI, Nashipur, Dinajpur, Bangladesh \\ ${ }^{6}$ Institute of Food Science and Technology (IFST), Bangladesh Council of Scientific and Industrial Research \\ (BCSIR), Dhaka-1205, Bangladesh
}

\section{Article history:}

Received: 15 July 2020

Received in revised form: 27

August 2020

Accepted: 14 October 2020

Available Online: 24 January 2021

\section{Keywords:}

Jute,

Leaves,

HPLC,

Polyphenolic compounds,

Antioxidant

\section{DOI:}

https://doi.org/10.26656/fr.2017.5(1).358

\begin{abstract}
Jute leaves (Corchorus spp.) have been used as a medicinal plant for the treatment of various diseases. The study was investigated on the antioxidant activities and HPLC profiling of polyphenolic compounds in ethanol extract of Corchorus olitorius $(C$. olitorius) and Corchorus capsularis (C. capsularis) leaves. The total antioxidant capacity was evaluated by phosphomolybdenum method and Identification and quantification of polyphenolic compounds were performed using HPLC-DAD system. The results indicated that eight polyphenolic compounds were found in the $C$. capsularis leaves but $C$. olitorius leaves contain six polyphenolic compounds. In fact, major identified polyphenolic compounds of C. capsularis leaves were caffeic acid (CA), 55.93 \pm 0.13 ; trans-ferulic acid (FA), 58.02 \pm 0.18 ; rutin hydrate (RH), 32.16 \pm 0.08 ; ellagic acid (EA), 53.65 \pm 0.11 and quercetin hydrate (QU), $46.17 \pm 0.09 \mathrm{mg} / 100 \mathrm{~g}$ of dry extract respectively. Whereas in $C$. olitorius leaves which were rutin hydrate $(\mathrm{RH}), 152.17 \pm 0.51$; ellagic acid (EA), $143.27 \pm 0.58$ and quercetin hydrate (QU), $292.83 \pm 0.73 \mathrm{mg} / 100 \mathrm{~g}$ of dry extract respectively. The results showed that $C$. capsularis leaves contained high level of total antioxidant capacity $(214.32 \pm 1.95 \mathrm{mg}$ of ascorbic acid/g of dry extract) than that of $C$. olitorius (165.66 $\pm 1.30 \mathrm{mg}$ of ascorbic acid/g of dry extract) leaves. The overall data suggested that $C$. olitorius and $C$. capsularis leaves contain a significant amount of several polyphenolic compounds that could be used as a natural antioxidant for functional foods.
\end{abstract}

\section{Introduction}

Jute (Corchorus spp.) is a cash crop in Bangladesh being cultivated in $10 \%$ of agricultural land area (Islam, 2019). It is cultivated in many other countries like as India, Myanmar, Nepal, China, Taiwan, Thailand, Vietnam, Cambodia, Brazil, etc. C. olitorius jute namely is Tossa Jute and C. capsularis jute namely is White Jute (Islam, 2013).

Demand for medicinal plants is increasing in both developed and developing countries due to the growing recognition of natural products being equally effective, safe, non-narcotic, affordable and has no side effects.
One such medicinal plant part is jute leaves (Islam, 2013). Young shoots and leaves are eaten as vegetable and food ingredients and have long been used as medicinal folk remedies in East Asia and Africa. Healthflourishing effects of plant-derived secondary metabolites in human health, including antioxidative, anticarcinogenic, antibiotic, and pharmacological effects, are well documented (Lee et al., 2015). C. olitorius leaves are used in the treatment of fever, tumors, pectoral pains, dysentery, aches, enteritis, cystitis, piles and dysuria (Adegoke and Adebayo-Tayo, 2009). C. capsularis leaves are also used in ayurvedic for ascites, piles, cystitis, dysuria, fever and gonorrhoea (Islam et 
al., 2013).

Leaves of $C$. olitorius have a large quantity of antioxidants compounds connected with various biological properties, which include diuretic, analgesic, antipyretic, antimicrobial activities, antitumor (Zakaria et al., 2006), phenolic antioxidative compounds (Azuma et al., 1999), hypoglycemic (Abo et al., 2008) and gastroprotective (Al Batran et al., 2013). On the other hand, $C$. capsularis leaves illustrated several pharmacological effects such as anticancer (Furumoto et al., 2002), antioxidant (Zakaria, 2007), antiinflammatory, antinociceptive, antipyretic (Zakaria et al., 2009) and antimicrobial (Mondal et al., 2017).

Reactive oxygen species (ROS) could be characterized as signaling molecules and lead to oxidative-induced damage to cell membranes, protein denaturation, DNA mutations and lipid peroxidation (Beckers and Spoel, 2006), which are related to some chronic diseases, like cancer, inflammation, cardiovascular diseases and others (Pietta, 2000). Antioxidants may be defined as complex determined compounds that function as defensive shields against several diseases (Nath et al., 2013). Phenolic compounds are an important group of plant-based biologically active compounds that strengthen the organism and prevent disease (Sun et al., 2002; Gharras, 2009). Plant polyphenols are secondary metabolites characterized by one or more hydroxyl groups binding to one or more aromatic rings (Zhou et al., 2019). Phenolic compounds have a particularly strong antioxidant effect (Hider et al., 2001; Scalbert et al., 2005; Pandey and Rizvi, 2009). Numerous epidemiologic literature has verified an important correlation between the consumption of phenolic compound-rich food and a decreased risk for developing cardiovascular and other diseases (Weichselbaum et al., 2010; Spencer, 2010).

Hence, in this study, we attempted to investigate the total antioxidant capacity and HPLC profiling of bioactive polyphenolic compounds in $80 \%$ ethanol extract of two varieties of jute leaves growing in Bangladesh.

\section{Materials and methods}

\subsection{Plant material}

The two varieties of jute Leaves, $C$. olitorius (O9897) and C. capsularis (CVL-1) were collected from Jute Seed Production and research centre, Bangladeh Jute Research Institute, Nashipur, dinajpur during June 2017. The leaves were properly washed to remove dirt and other impurities. After that, the leaves were dried under the shade. The dried leaves were powder by pulverizes. The sample was then saved in an airtight container and storage in the refrigerator until extraction.

\subsection{Extraction}

The two varieties of shade dried leaves were extracted in an orbital shaker with $80 \%$ ethanol for 24 hrs at room temperature to obtain ethanol extract of jute leaves. The extract was initially filtered in a cotton plug to get rid of the plant debris and next through Whatman filter paper no 1 . The solvent was removed using a rotary vacuum evaporator (R-215, Buchi, Switzerland) under reduced pressure. The concentrated filtrates were kept in the bottle at $-20^{\circ} \mathrm{C}$ prior to further analysis.

\subsection{Chemicals and reagents}

All the standards were purchased from SigmaAldrich (St. Louis, MO, USA) and reagent was collected from Scharlau (Spain) and Merck (Germany).

\subsection{Total antioxidant capacity}

The total antioxidant capacity of the $C$. olitorius and C. capsularis leaves sample extract were evaluated by the phosphomolybdenum assay method (Prieto et al., 1999) which is based on the reduction of Mo (VI) to Mo (V) and the subsequent formation of a green phosphateMo (V) complex in acidic condition. $0.3 \mathrm{~mL}$ of each extract $\left(1 \mathrm{mg} \mathrm{mL}^{-1}\right)$ was allowed to mix with $3.0 \mathrm{~mL}$ of the reagent solution $\left(0.6 \mathrm{M} \mathrm{H}_{2} \mathrm{SO}_{4}, 28 \mathrm{mM} \mathrm{Na}_{3} \mathrm{PO}_{4}, 4\right.$ $\mathrm{mM}$ ammonium molybdate). This reaction mixture was incubated at $95^{\circ} \mathrm{C}$ for 90 mins. After letting the solution cool back to room temperature, the absorbance was measured at $695 \mathrm{~nm}$ with a double beam UV/Visible spectrophotometer (Specord 205, Analytikjena, Germany) against a blank solution. The total antioxidant capacity was determined and expressed as $\mathrm{mg}$ ascorbic acid equivalents per gram of dry extract using the equation obtained from a standard ascorbic acid calibration curve.

\subsection{Identification and quantification of polyphenolic compounds by HPLC}

Identification and quantification of selected phenolic compounds in the $80 \%$ ethanol extract were determined by HPLC-DAD analysis as described by Hossain et al. (2016) with some modifications. It was carried out on a Dionex UltiMate 3000 system equipped with quaternary rapid separation pump (LPG-3400RS) and photodiode array detector (DAD-3000RS). The separation was performed using Acclaim ${ }^{\circledR} \mathrm{C}_{18}(5 \mu \mathrm{m})$ Dionex column $(4.6 \times 250 \mathrm{~mm})$ at $30^{\circ} \mathrm{C}$ with a flow rate of $1 \mathrm{~mL} / \mathrm{min}$ and an injection volume of $20 \mu \mathrm{L}$. The mobile phase consisted of acetonitrile (solvent A), acetic acid solution pH 3.0 (solvent B), and methanol (solvent C) with the 
gradient elution program of $5 \% \mathrm{~A} / 95 \% \mathrm{~B}$ (0-10 mins), $10 \% \mathrm{~A} / 90 \% \mathrm{~B}$ (11-15 mins), 15\% A/70\% B/15\% C (1625 mins), $20 \% \mathrm{~A} / 60 \% \mathrm{~B} / 20 \% \mathrm{C}$ (26-30 mins), $30 \%$ $\mathrm{A} / 40 \% \mathrm{~B} / 30 \% \mathrm{C}(31-35$ mins), $40 \% \mathrm{~A} / 50 \% \mathrm{~B} / 10 \% \mathrm{C}$ (36-40 mins), and 5\% A/95\% B (41-45 mins). The UV detector was set to $280 \mathrm{~nm}$ for 25.0 mins, changed to 320 $\mathrm{nm}$ for 32.0 mins, again change to $280 \mathrm{~nm}$ for $34 \mathrm{mins}$ and finally to $380 \mathrm{~nm}$ for 35 mins and held for the rest of the analysis period while the diode array detector was set at an acquisition range from $200 \mathrm{~nm}$ to $700 \mathrm{~nm}$. For the preparation of calibration curve, a standard stock solution was prepared in methanol containing gallic acid, vanillic acid, myricetin, rosmarinic acid $(8 \mu \mathrm{g} / \mathrm{mL}$ each); caffeic acid, syringic acid, vanillin, trans-ferulic acid, kaempferol $(6 \mu \mathrm{g} / \mathrm{mL}$ each); (+)-catechin hydrate, (-)epicatechin $(10 \mu \mathrm{g} / \mathrm{mL}$ each); pyrogallol, ellagic acid (48 $\mu \mathrm{g} / \mathrm{mL}$ each); $p$-coumaric acid $(3 \mu \mathrm{g} / \mathrm{mL})$; rutin hydrate $(12 \mu \mathrm{g} / \mathrm{mL})$ and quercetin hydrate $(4 \mu \mathrm{g} / \mathrm{mL})$. A solution of the ethanol extracts was prepared in methanol having the concentration of $10 \mathrm{mg} / \mathrm{mL}$. Prior to HPLC analysis, all the solutions (mixed standards, sample, and spiked solutions) were filtered through $0.20 \mu \mathrm{m}$ syringe filter (Sartorius, Germany) and then degassed in an ultrasonic bath (Hwashin, Korea) for 15 mins. Data acquisition, peak integration, and calibrations were calculated with Dionex Chromeleon software (Version 6.80 RS 10).

\section{Results and discussion}

\subsection{Total antioxidant capacity}

Phosphomolybdate assay is an easy and well-known technique based on the reduction of Molybdenum (VI) to Molybdenum (V) by forming phosphate-Molybdenum (V) complex which is green in color with maximal absorption at a wavelength of $695 \mathrm{~nm}$. Total antioxidant capacity of $C$. olitorius and C. capsularis is illustrated in Table 1. Results showed that C. capsularis leaves contained high total antioxident capacity $(214.32 \pm 1.95$ $\mathrm{mg}$ of ascorbic acid/g of dry extract) then $C$. olitorius (165.66 $\pm 1.30 \mathrm{mg}$ of ascorbic acid/g of dry extract). Total antioxidant capacity is an analyte frequently used to assess the antioxidant status of biological samples and can evaluate the antioxidant response against the free radicals produced in a given disease (Rubio et al., 2016).

Table 1. Total antioxidant capacity of $80 \%$ ethanol extract of Jute leaves ( $\mathrm{mg}$ of ascorbic acid/g of dry extract)

\begin{tabular}{cc}
\hline Jute Leaves & Total antioxidant capacity \\
\hline C. olitorius & $165.66 \pm 1.30$ \\
C. capsularis & $214.32 \pm 1.95$ \\
\hline
\end{tabular}

3.2 Identification and quantification of polyphenols in Corchorus olitorius and Corchorus capsularis leaves

Identification and quantification of individual polyphenolic compounds in the $80 \%$ ethanolic extracts of $C$. olitorius and $C$. capsularis were analysed by HPLC. The chromatographic separations of polyphenols in standard and $80 \%$ ethanolic extracts of C. olitorius and $C$. capsularis are shown in Figures 1,2 and 3 respectively. The content of each polyphenolic compound found in the $80 \%$ ethanolic extracts of $C$. olitorius and $C$. capsularis was calculated from the corresponding calibration curve and presented as the mean of five determinations as shown in Tables 2 and 3.

The analysis of the results of HPLC-DAD allowed the detection of six and eight polyphenolic compounds from C. olitorius and C. capsularis leaves respectively. The experimental results indicated that $80 \%$ ethanolic extract of C. olitorius leaves contained an especially high concentration of rutin hydrate, ellagic acid, and quercetin hydrate $(152.17 \pm 0.51,143.27 \pm 0.58$, and $292.83 \pm 0.73$ $\mathrm{mg} / 100 \mathrm{~g}$ of dry extract, respectively) than that of $C$. capsularis $(32.16 \pm 0.08,53.65 \pm 0.11$, and $46.17 \pm 0.09$ $\mathrm{mg} / 100 \mathrm{~g}$ of dry extract, respectively). It was also shown that caffeic acid and vanillin were detected both in the $80 \%$ ethanol extract of $C$. olitorius and C. capsularis but the concentration of caffeic acid was at the moderate amount $(51.06 \pm 0.11$ and $55.93 \pm 0.13 \mathrm{mg} / 100 \mathrm{~g}$ of dry extract) and vanillin at a lower amount $(5.18 \pm 0.04$ and $1.04 \pm 0.01 \mathrm{mg} / 100 \mathrm{~g}$ of dry extract) shown in Tables 2 and 3. It was also found that vanillic acid, trans-ferulic acid and rosmarinic acid $(13.28 \pm 0.05,58.02 \pm 0.18$ and $3.54 \pm 0.02 \mathrm{mg} / 100 \mathrm{~g}$ of dry extract, respectively) were detected only in the $80 \%$ ethanol extract of C. capsularis leaves and on the other side kaempferol $(13.32 \pm 0.07$ $\mathrm{mg} / 100 \mathrm{~g}$ of dry extract) was detected only in the $80 \%$ ethanol extract of $C$. olitorius at a lower concentration shown in Tables 2 and 3 . The major identified polyphenolic compounds of $C$. olitorius were rutin hydrate, ellagic acid and quercetin hydrate. These compounds display interesting biological properties, such as antioxidant as well as anti-inflammatory and anticancer activities (Selloum et al., 2003; Vattem and Shetty, 2005; Anand David et al., 2016; Ganeshpurkar and Saluja, 2017). The previous study reported the presence of ethanol, ethanol: water (50:50) and water extract of $C$. olitorius leaves contain caffeic acid $(229.56,146.02$ and $306.43 \mathrm{mg} / \mathrm{kg}$ ), quercetin (52.01, 35.26 and $3.13 \mathrm{mg} / \mathrm{kg}$ ) and kaempferol (18.28, 29.39 and $16.24 \mathrm{mg} / \mathrm{kg}$ ) etc (Ben Yakouba et al., 2018). Which is lower than our present study. In C. capsularis leaves, the most abundant polyphenolic compounds were caffeic acid, trans-ferulic acid, rutin hydrate, ellagic acid and quercetin hydrate. These compounds have also a noticeable Pharmacological propriety such as antioxidant, anti-inflammatory and anticancer activities (Selloum et al., 2003; Vattem and Shetty, 2005; Kumar and Pruthi, 2014; Anand David et al., 2016; 


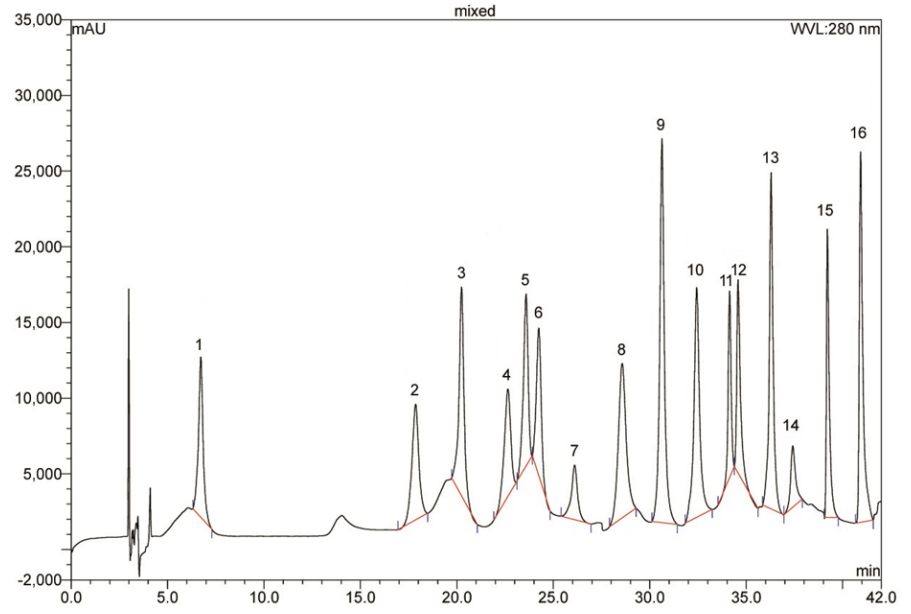

Figure 1. HPLC chromatogram of a standard mixture of polyphenolic compounds. Peaks: 1, gallic acid; 2, pyrogallol; 3, (+)-catechin hydrate; 4, vanillic acid; 5, caffeic acid; 6, syringic acid; 7, (-)-epicatechin; 8, vanillin; 9, p-coumaric acid; 10, trans-ferulic acid; 11, ellagic acid; 12, rutin hydrate; 13 , rosmarinic acid; 14 , myricetin; 15 , quercetin hydrate; 16 , kaempferol

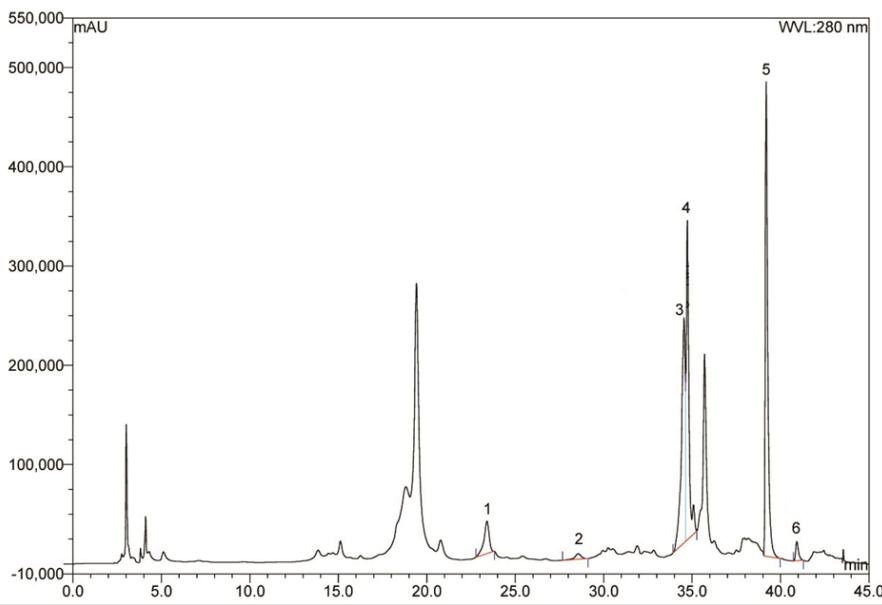

Figure 2. HPLC chromatogram of $80 \%$ ethanolic extract of $C$. olitorius leaves. Peaks: 1, caffeic acid (CA); 2, vanillin (VL); 3 , rutin hydrate $(\mathrm{RH})$; 4, ellagic acid $(\mathrm{EA}) ; 5$, quercetin hydrate (QU); 6, kaempferol (KF)

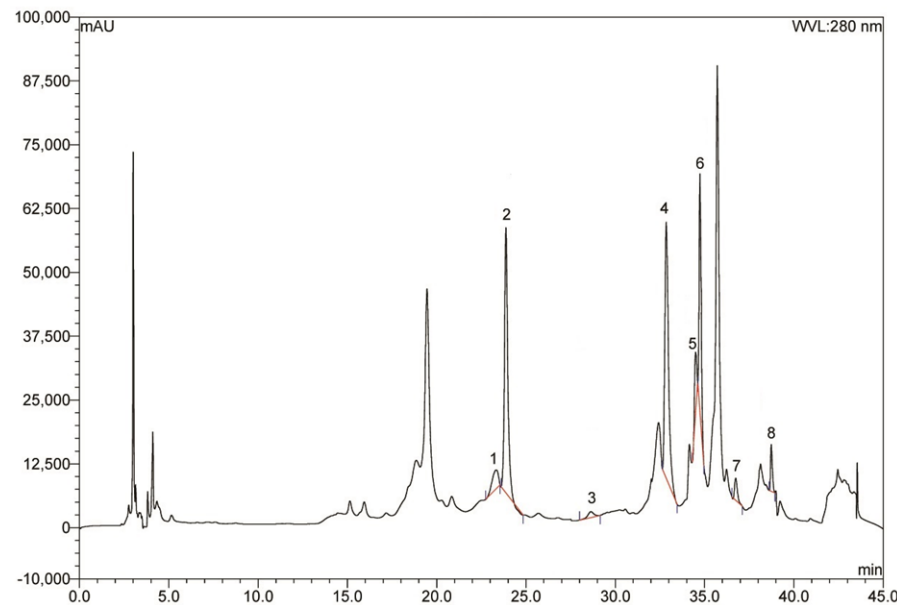

Figure 3. HPLC chromatogram of $80 \%$ ethanol extract of $C$. capsularis leaves. Peaks: 1, vanillic acid (VA); 2, caffeic acid (CA); 3, vanillin (VL); 4, trans-ferulic acid (FA); 5, rutin hydrate (RH); 6, ellagic acid (EA); 7, rosmarinic acid (RA); 8, quercetin hydrate $(\mathrm{QU})$
Ganeshpurkar and Saluja, 2017; Espíndola et al., 2019). In this context, Mosihuzzaman et al. (1986) showed that $p$-coumaric, caffeic, vanillic, ferulic acid and $p$ hydroxybenzoic acids were present in the $80 \%$ aqueous ethanol extract of C. capsularis in unretted bark and stem of jute. The antioxidant is generally used to evaluate the total antioxidant power of single compounds and complex mixtures of different plants (Huang et al., 2008). Antioxidant activity depends on the present of polyphenolic compounds (Materska and Perucka, 2005). Therefore, significant results of total antioxidant capacity of both extracts may be due present of different polyphenolic compounds.

Table 2. Contents of polyphenolic compounds in $80 \%$ ethanol extract of $C$. olitorius leaves $(\mathrm{n}=5)$

\begin{tabular}{ccc}
\hline Polyphenolic & Content $(\mathrm{mg} / 100 \mathrm{~g}$ of dry extract $)$ & $\%$ RSD \\
\hline CA & 51.06 & 0.11 \\
VL & 5.18 & 0.04 \\
RH & 152.17 & 0.51 \\
EA & 143.27 & 0.58 \\
QU & 292.83 & 0.73 \\
KF & 13.32 & 0.07 \\
\hline
\end{tabular}

RSD: Relative Standard Deviation

Table 3. Contents of polyphenolic compounds in $80 \%$ ethanol extract of $C$. capsularis leaves $(\mathrm{n}=5)$.

\begin{tabular}{ccc}
\hline Polyphenolic & Content $(\mathrm{mg} / 100 \mathrm{~g}$ of dry extract $)$ & \% RSD \\
\hline VA & 13.28 & 0.05 \\
CA & 55.93 & 0.13 \\
VL & 1.04 & 0.01 \\
FA & 58.02 & 0.18 \\
RH & 32.16 & 0.08 \\
EA & 53.65 & 0.11 \\
RA & 3.54 & 0.02 \\
QU & 46.17 & 0.09 \\
\hline
\end{tabular}

RSD: Relative Standard Deviation

\section{Conclusion}

The results of the present study indicated that, $C$. olitorius and $C$. capsularis leaves exhibit a significant amount of total antioxidant capacity and polyphenolic compounds.

\section{Conflict of interest}

The authors declare no conflict of interest.

\section{Acknowledgments}

We are thankfully acknowledged Chemical Research Division, BCSIR laboratories, Dhaka, Bangladesh Council of Scientific and Industrial Research (BCSIR), Dhaka-1205, Bangladesh for laboratory facilities. 


\section{References}

Abo, KA., Fred-jaiyesimi, A.A. and Jaiyesimi, A.E.A. (2008). Ethnobotanical studies of medicinal plants used in the management of diabetes mellitus in South Western Nigeria. Journal of Ethnopharmacology, 115(1), 67-71. https:// doi.org/10.1016/j.jep.2007.09.005

Adegoke, A.A. and Adebayo-Tayo, B.C. (2009). Phytochemical composition and antimicrobial effects of Corchorous olitorius leaf extracts on four bacterial isolates. Journal of Medicinal Plants Research, 3(3), 155-159.

Al Batran, R., Al-bayaty, F., Abdulla, M.A., Al-Obaidi, M.M.J., Hajrezaei, M., Hassandarvish, P., Fouad, M., Golbabapour, S. and Talaee, S. (2013). Gastroprotective effects of Corchorus olitorius leaf extract against ethanol-induced gastric mucosal hemorrhagic lesions in rats. Journal of Gastroenterology and Hepatology, 28(8), 13211329. https://doi.org/10.1111/jgh.12229

Anand David, A.V., Arulmoli, R. and Parasuraman, S. (2016). Overviews of biological importance of quercetin: A bioactive flavonoid. Pharmacognosy Review, 10(20), 84-89. https://doi.org/10.4103/09737847.194044

Azuma, K., Nakayama, M., Koshioka, M., Ippoushi, K., Yamaguchi, Y., Kohata, K., Yamauchi, Y., Ito, H. and Higashio, H. (1999). Phenolic antioxidants from the leaves of Corchorus olitorius L. Journal of Agricultural and Food Chemistry, 47(10), 39633966.

Beckers, G.J.M. and Spoel, S.H. (2006). Fine-tuning plant defence signalling: salicylate versus jasmonate. Plant Biology, 8(1), 1-10. https://doi.org/10.1055/s2005-872705

Ben Yakouba, A.R., Abdehedic, O., Jridic, M., Elfallehd, W., Nasric, M. and Ferchichie, A. (2018). Flavonoids, phenols, antioxidant and antimicrobial activities in various extracts from Tossa jute leave (Corchorus olitorius L.). Industrial Crops and Products, 118, 206-213. https://doi.org/10.1016/ j.indcrop.2018.03.047

Espíndola, K.M.M., Ferreira, R.G., Narvaez, L.E.M., Silva Rosario, A.C.R., da Silva, A.H.M., Silva, A.G.B., Vieira, A.P.O. and Monteiro, M.C. (2019). Chemical and Pharmacological Aspects of Caffeic Acid and Its Activity in Hepatocarcinoma. Frontiers in Oncology, 9, 541. https://doi.org/10.3389/ fonc. 2019.00541

Furumoto, T., Wang, R., Okazaki, K., Hasan, A.F.M.F., Ali, M.I., Kondo, A. and Fuqui, H. (2002). Antitumor promoters in leaves of jute (Corchorus capsularis and Corchorus olitorius). Food Science and Technology Research, 8(3), 239-243. https:// doi.org/10.3136/fstr.8.239

Ganeshpurkar, A. and Saluja A.K. (2017). The Pharmacological Potential of Rutin. Saudi Pharmaceutical Journal, 25(2), 149-164. https:// doi.org/10.1016/j.jsps.2016.04.025

Gharras, H.E. (2009). Polyphenols: food sources, properties and applications-a review. International Journal of Food Science and Technology, 44(12), 2512-2518. ttps://doi.org/10.1111/j.13652621.2009.02077.x

Hider, R.C., Liu, Z.D. and Khodr, H.H. (2001). Metal chelation of polyphenols. Methods in Enzymology, 335, 190-203. https://doi.org/10.1016/S0076-6879 (01)35243-6

Hossain, H., Rahman S.E., Akbar, P.N., Khan, T.A., Rahman, M.M. and Jahan I.A. (2016). HPLC profiling, antioxidant and in vivo anti-inflammatory activity of the ethanol extract of Syzygium jambos available in Bangladesh. BMC Research Notes, 9(1), 1-8. https://doi.org/10.1186/s13104-016-2000-z

Huang, S.S., Huang, G.J., Ho, Y.L., Lin, Y.H., Hung, H.J., Chang, T.N., Chang. M.J., Chen, J.J. and Chang, Y.S. (2008). Antioxidant and antiproliferative activities of the four Hydrocotyle species from Taiwan. Botanical Studies, 49(4), 311322.

Islam, M.M. (2013). Biochemistry, medicinal and food values of jute (Corchorus capsularis L. and $C$. olitorius L.) leaf: a review. International Journal of Enhanced Research in Science Technology and Engineering, 2(11), 35-44.

Islam, M.M. (2019). Varietal advances of jute, kenaf and mesta crops in Bangladesh: A review. International Journal of Bioorganic Chemistry, 4(1), 24-41. https://doi.org/10.11648/j.ijbc.20190401.15

Islam, M.T., Mendes de Freitas, R., Sultana, I., Mahmood, A., Hossain, J.A., Homa, Z. and Chowdhury, M.M.U. (2013). A comprehensive review of Corchorus capsularis: a source of nutrition, essential phytoconstituents and biological activities. Journal of Biomedical and Pharmaceutical Research, 2(1), 1-8.

Kumar, N. and Pruthi, V. (2014). Potential applications of ferulic acid from natural sources. Biotechnology Reports, 4, 86-93. https://doi.org/10.1016/ j.btre.2014.09.002

Lee, Y.H., Choo, C., Watawana, M.I., Jayawardena, N. and Waisundara, V.Y. (2015). An appraisal of eighteen commonly consumed edible plants as functional food based on their antioxidant and starch 
hydrolase inhibitory activities. Journal of the Science of Food and Agriculture, 95(14), 2956-2964. https:// doi.org/10.1002/jsfa.7039

Materska, M. and Perucka I. (2005). Antioxidant activity of the main phenolic compounds isolated from hot pepper fruit (Capsicum annuum L.). Journal of Agricultural and Food Chemistry, 53(5), 1750-1756. https://doi.org/10.1021/jf035331k

Mondal, T.K., Sohel, M.D., Kawsar, M.H. and Laso, D. (2017). Phytochemical and antimicrobial investigations of different fractions of the methanolic extract of Corchorus capsularis leaves. African Journal of Pharmacy and Pharmacology, 11(17), 209-216. https://doi.org/10.5897/AJPP2017.4747

Mosihuzzaman, M., Chowdhury, T.A., Mollah, A.H., Theander, O. and Lundgren, L.N. (1986). Phenolic Acids in the Jute Plant (Corchorus capsularis). Journal of the Science of Food and Agriculture, 37 (10), 955-960. https://doi.org/10.1002/ jsfa. 2740371002

Nath, R., Roy, S., De, B. and Duttachoudhury, M. (2013). Anticancer and antioxidant activity of Croton: a review. International Journal of Pharmacy and Pharmaceutical Sciences, 5, 63-70.

Pandey, K.B. and Rizvi, S.I. (2009). Plant polyphenols as dietary antioxidants in human health and disease. Oxidative Medicine and Cellular Longevity, 2(5), 270-278. https://doi.org/10.4161/oxim.2.5.9498

Pietta, P.G. (2000). Flavonoids as antioxidants. Journal of Natural Products, 63(7), 1035-1042. https:// doi.org/10.1021/np9904509

Prieto, P., Pineda, M. and Aquilar, M. (1999). Spectrophotometric quantitation of antioxidant capacity through the formation of a Phosphomolybdenum Complex: Specific application to the determination of vitamin E. Analytical Biochemistry, 269(2), 337-341. https:// doi.org/10.1006/abio.1999.4019

Rubio, C.P., Hernández-Ruiz, J., Martinez-Subiela, S., Tvarijonaviciute, A. and Ceron J.J. (2016). Spectrophotometric assays for total antioxidant capacity (TAC) in dog serum: an update. $B M C$ Veterinary Research, 12, $166 . \quad \mathrm{https} / / /$ doi.org/10.1186/s12917-016-0792-7

Scalbert, A., Johnson, I.T. and Saltmarsh, M. (2005). Polyphenols: antioxidants and beyond. American Journal of Clinical Nutrition, 81(1), 215S-217S. https://doi.org/10.1093/ajcn/81.1.215S

Selloum, L., Bouriche, H., Tigrine, C. and Boudoukha, C. (2003). Anti-inflammatory effect of rutin on rat paw oedema and on neutrophils chemotaxis and degranulation. Experimental and Toxicologic
Pathology, 54(4), 313-318. https:// doi.org/10.1078/0940-2993-00260

Spencer, J.P.E. (2010). The impact of fruit flavonoids on memory and cognition. British Journal of Nutrition, 104(3), S40-S47. https://doi.org/10.1017/ S0007114510003934

Sun, J., Chu. Y.F., Wu, X. and Liu, R.H. (2002). Antioxidant and antiproliferative activities of common fruits. Journal of Agricultural and Food Chemistry, 50(25), 7449-7454. https:// doi.org/10.1021/jf0207530

Vattem, D.A. and Shetty K. (2005). Biological functionality of ellagic acid: A review. Journal of Food Biochemistry, 29(3), 234-266. https:// doi.org/10.1111/j.1745-4514.2005.00031.x

Weichselbaum, E., Wyness, L. and Stanner, S. (2010). Apple polyphenols and cardiovascular disease- a review of the evidence. Nutrition Bulletin, 35(2), 92101.

https://doi.org/10.1111/j.14673010.2010.01822.x

Zakaria, Z.A., Somchit, M.N., Zaiton, H., Mat Jais, A.M., Sulaiman, M.R., Farah, W.O., Nazaratulmawarina, R. and Fatimah, C.A. (2006). The in vitro antibacterial activity of Corchorus olitorius extracts. International Journal of Pharmacology, 2(2), 213-215. https:// doi.org/10.3923/ijp.2006.213.215

Zakaria, Z.A. (2007). Free radical scavenging activity of some plants available in Malaysia. Iranian Journal of Pharmacology and Therapeutics, 6(1), 87-91. https://doi.org/10.3742/OPEM.2006.6.1.058

Zakaria, Z.A., Kumar, G.H., Raden Mohd. Nor, R.N.S., Sulaiman, M.R., Fatimah, C.A., Mat Jais, A.M., Somchit, M.N. and Ismail, M.S. (2009). Antinociceptive, anti-inflammatory and antipyretic properties of an aqueous extract of Corchorus capsularis leaves in experimental animal models. Pharmaceutical Biology, 47(2), 104-110. https:// doi.org/10.1080/13880200802436539

Zhou, Y., Jiang, Z., Lu, H., Xu, Z., Tong, R., Shi, J. and Jia, G. (2019). Recent Advances of Natural Polyphenols Activators for Keap1-Nrf2 Signaling Pathway. Chemistry and Biodiversity, 16(11), e1900400. https://doi.org/10.1002/cbdv.201900400 